\title{
Opioid Use and Intimate Partner Violence: a Systematic Review
}

\author{
Rebecca Stone $^{1}$ - Emily F. Rothman ${ }^{2}$
}

Published online: 1 May 2019

(C) Springer Nature Switzerland AG 2019

\begin{abstract}
Purpose of Review The goal of this review was to answer two questions: A) What is the prevalence of opioid use in samples of people who are victims and/or perpetrators of intimate partner violence (IPV), and B) what is the prevalence of IPV among those who have used opioids?

Recent Findings There were five times as many research studies of IPV in people who use opioids (B) than of opioids in IPVexperienced people (A). Across the five studies that reported estimates of opioid use among IPV-experienced people, for victimization, estimates ranged from $2.4 \%$ having an opioid use disorder (OUD) to 46-50\% having had a prescription for opioid as an analgesic in the past 5 years. For perpetration, there was a sole study which found that $1.5 \%$ of a sample of perpetrators of IPV reported having an OUD. The prevalence of IPV victimization among women who had used opioids was 36-94\% in their lifetimes, and $32-75 \%$ in the past year. For men who had used opioids, the prevalence of IPV perpetration ranged from $15 \%$ perpetrating severe physical IPV or a gun/knife threat in the past year to 58\% reporting any IPV perpetration in their lifetimes. Summary IPV is frequent among people who use opioids. Opioid use appears to be elevated in IPV victims and/or perpetrators as compared with the general population. Research is needed on the prevalence of opioid use in samples of IPV-experienced people, including initiation of use and how opioid use influences risk for IPV.
\end{abstract}

Keywords Opioids $\cdot$ Intimate partner violence $\cdot$ Substance use disorder $\cdot$ Opiates $\cdot$ Systematic review

\section{Introduction}

The USA is currently facing an epidemic of opioid misuse and overdose fatalities [1]. In 2016, 42,249 people in the USA died from drug overdoses involving opioids, and opioid-related poisonings resulted in 140,077 emergency department visits and 78,840 hospitalizations [2]. In response, the National Institutes of Health $(\mathrm{NIH})$ is greatly increasing funding for research to combat the opioid crisis, including research to identify social

This article is part of the Topical Collection on Injury Epidemiology

Rebecca Stone

rstone@suffolk.edu

Emily F. Rothman

erothman@bu.edu

1 Sociology Department, Suffolk University, 7th Floor, 73 Tremont St, Boston, MA 02108, USA

2 Department of Community Health Sciences, Boston University School of Public Health, Boston, MA, USA factors that put patients at risk for opioid use disorder (OUD) [1]. Evidence suggests that there are gender differences in the nonmedical use of prescription opioids and heroin, as well as gender differences in the progression through drug use milestones [3], and these gender differences may reflect social, rather than biological, factors. Nonmedical use of prescription opioids has been decreasing in recent years while use of heroin has been increasing [4]. Between 2002 and 2013, there was a $100 \%$ increase in heroin use for women, compared with a $50 \%$ increase for men [5]. A recent study shows that women are increasing their use of heroin at a much faster rate than men (15 per 1000 persons vs. 8 per 1000 persons) and decreasing their use of nonmedical prescription opioids at a slower rate (6 vs. 7 per 1000 persons) [6]. Reasons why women's heroin use is increasing, and increasing more quickly than men's, have not yet been explicated.

While the increases in opioid use and opioid-related harms emerged as an acute epidemic in the past decade [7-10], the USA has also faced a chronic struggle with high rates of intimate partner violence (IPV) for at least a half-century [11, 12]. According to the most recent report from the National Intimate Partner and Sexual Violence Survey (NISVS), 
$37.3 \%$ of women and $30.9 \%$ of men in the USA have experienced intimate partner sexual or physical violence, and/or intimate partner-perpetrated stalking, in their lifetimes [13]. Approximately $6.6 \%$ of women and $6.4 \%$ of men reported experiencing IPV within the past 12 months [13]. As a consequence of victimization, $27.4 \%$ of women and $11.0 \%$ of men reported an IPV-related impact including injury, fear, concern for safety, or needing assistive services. IPV is estimated to cost the USA in excess of $\$ 8$ billion each year (in 2003 dollars), which includes not only the cost of direct medical and mental health care services, but also the cost of lost productivity from paid work and loss of lifetime earnings [14] (see also [15]).

A hidden cost of the IPV epidemic is the bidirectional relationship between substance abuse disorders (SUDs) and IPV. For example, one meta-analytic review found that IPV perpetration occurs three times more often in couples where one or the other uses illegal drugs, where illegal drugs were categorized as marijuana, cocaine, opiates, sedatives/anxiolytics/hypnotics, hallucinogens, stimulants, other, and mixed drugs [16]. Among women experiencing IPV, another metaanalysis finds the prevalence of co-occurring drug abuse or dependence ranges from 7 to $25 \%$ [17], and past-year SUD is higher among women experiencing physical IPV victimization in their current relationship (3.6\%) than women who were not in violent relationships $(0.7 \%)$ [18]. At least two explanations for the co-occurrence of IPV victimization and SUDs are suggested by empirical research. First, IPV causes physical pain, and some individuals may use substances to cope with physical pain [19, 20]. Physical, sexual, and even psychological IPV victimization are associated with long-term somatic sequelae including headaches, back pain, gynecological problems, abdominal problems, and chronic disease [21-25] Second, IPV victimization is associated with post-traumatic stress disorder (PTSD) [17, 26-28], anxiety, and depression [29-31], which each elevates risk for substance use disorder (SUD) [17, 32-34]. The association between SUDs and IPV perpetration has been explored extensively elsewhere [35-38]), but possible explanations include that the pharmacological effects of some substances may increase aggression and irritability $[39,40]$, intoxication may cause cognitive distortions and misperceptions about partners' behavior [39], SUDs may cause or worsen impulse control problems [41-43], and that couples in which one partner has an SUD may be prone to higher levels of conflict about the substance use, money, or other topics [44-46].

The percentage of IPV survivors or perpetrators who use opioids has been studied relatively rarely, considering the more extensive literature on IPV and SUDs of any type. However, now that the USA and other nations are facing an opioid use disorder (OUD) crisis in addition to unacceptably high rates of IPV, it is logical to assess whether IPV may contribute to OUDs, or OUDs contribute to IPV, and how commonly any association between the two may actually be attributable to underlying other factors (i.e., confounders). These three possibilities are not mutually exclusive and may each be true. Large-scale epidemiological studies would help determine the percentage of OUDs that may be, even in part, attributable to IPV — and vice versa - but before such studies can be undertaken, a thorough review of the existing literature that has documented any association between OUDs and IPV is needed. Therefore, the purpose of this systematic review was to identify and summarize the body of quantitative research studies on this topic.

\section{Methods}

\section{Search Strategy}

We reviewed the peer-reviewed, published literature for all studies that quantitatively examined intimate partner violence (IPV) in relation to opioid use where opioid use was assessed and reported separately from other forms of substance use (i.e., results did not combine opioid use with other substance use). Opioids include heroin, synthetic opioids such as fentanyl, and prescription opioid analgesics such as oxycodone, codeine, and morphine [47]. To be included, articles had to include either (a) the prevalence of IPV among some population of people who use opioids or (b) the prevalence of opioid use among some population of IPV-experienced people (victims or perpetrators). Further, articles had to be written in English, French, or Spanish. Initially, we limited inclusion to articles that were published in 2013 or later, but because that yielded only 11 articles, we expanded our criteria to include publication dates from 1998 to present.

We searched the peer-reviewed literature using the ISI Web of Knowledge database, which includes citations from Medline, BIOSIS, and other databases, and the PsycINFO database for the period between January 1, 1998, and July 2018. Our IPV-related keywords were "intimate partner violence," "domestic violence," "partner abuse," "dating violence," "battering," and "battered." Our opioid keywords were "opioids," "opiates," "heroin," "oxycontin," "prescription drug misuse," "methadone," and "buprenorphine." We searched for all possible combinations of each IPV keyword with each opioid keyword.

We next screened the titles of articles for probable relevance to our review topic, and screened all abstracts of potentially relevant articles. There were 408 unique articles identified from our search terms, and of these, 128 were screened by abstract to determine their suitability for inclusion. The full text of 80 articles was reviewed. Articles were excluded from further consideration if they did not separately and specifically measure IPV (e.g., if IPV was grouped with other types of violence; $n=13$ ) or of opioids (e.g., if opioids were included 
in a category with other drugs; $n=24)$. Five articles were excluded because IPV and opioid use were included in the underlying studies, but only as independent variables predicting something not relevant to this review, and no bivariate information was provided. An additional five articles were excluded because the sample had been selected on both variables of interest, so $100 \%$ of the samples had both IPV and opioid use by design. Finally, two articles were excluded because they duplicated estimates from another article included in the review or in one case, because a question of scientific fraud has been raised about the author's research in this area (Fig. 1). This resulted in a final sample of 31 articles (Table 1).

To assess patterns in study results, the following information was abstracted (Table 1): author name and year of publication, sample size and sample population, years of data collection, age of study participants, and key findings. Studies were grouped into two categories by their key findings: studies that answered the question (Question A) "What is the prevalence of opioid use, given IPV?" and (Question B) "What is the prevalence of IPV, given opioid use?" Within these categories, studies are arranged alphabetically by the first author in Table 1. While we considered attempting to organize studies by whether their focus was on IPV victimization or perpetration, many articles reported findings on both. In addition, while we considered attempting to organize articles based on whether the type of IPV studied was physical, sexual, or psychological, multiple articles reported on more than one form of IPV.

\section{Results}

We identified five studies with information about the prevalence of opioid use in samples of people who were either IPV victimization- or perpetration-experienced [48-52], and 26 studies that provided information about the prevalence of IPV victimization or perpetration in samples of people with opioid use [53-56, 57•, 58-69, 70•, 71•, 72-74, 75, 76, 77]. Of these, 19 were studies of people in methadone treatment (MT) [53-55, 58-67, 71 • 73, 74, 75•, 78], and the remaining seven were of people who used emergency medical services $(n=2)[68,77]$, were court-involved for drug use $(n=2)$ [56, 57•], partners of men who used opioids $(n=2)[72,76]$, or were on probation or parole $(n=1)$ [70॰].

Of the studies reviewed, 11 were published in the past 5 years, an additional eight studies were published within the past decade, and 12 were published between 1998 and 2008. Of those published between 1998 and 2008, all were on the prevalence of IPV among opioid users, and all but one was from a prolific research team lead by Dr. Nabila ElBassel. Papers published from El-Bassel's various datasets utilized the identical sample of 416 women in three of the studies included in this review $[60,63,66]$, and the identical sample of 356 men in two of the studies $[62,69]$; the findings reported in the included studies are not duplicative of one another.

\section{Prevalence of Opioid Use Among IPV-Experienced People}

Across the five studies that reported estimates of opioid use among IPV-experienced people, for victimization, estimates ranged from $2.4 \%$ having an opioid use disorder (OUD) to 46-50\% having had a prescription for opioid as an analgesic in the past 5 years. For perpetration, there was a sole study which found that $1.5 \%$ of a sample of perpetrators of IPV reported having an OUD. Of the five studies, no two studies defined opioid use in the same way. One studied being in substance abuse treatment for heroin use [48], another having a diagnosed OUD [49], another self-reported heroin use in the past year [51], a fourth past-month self-reported opioid use [52], and a final study of medical records examined prescriptions of opioids as analgesic [50]. Because of the paucity of research studies on this topic and the dissimilarity in the assessment of opioid use, meta-analysis on this topic is not now possible. The relative risk (RR) of opioid use among IPV victims as compared with non-victims was estimated to be 2.37-3.11 in one study [50].

\section{Prevalence of IPV Victimization and Perpetration Among People Who Use Opioids}

There were 26 studies that provided $\geq 1$ estimate of the prevalence or relative risk of a form of IPV in a sample of people who had used opioids. Of these, 20 provided $\geq 1$ estimate on IPV victimization and 9 provided $\geq 1$ estimate on perpetration - several provided estimates of both, and one studied "dating violence involvement," operationalized as either victimization or perpetration (see Table 1). There were 18 studies on IPV victimization of women and two studies on IPV perpetration by women. One study provided an estimate of IPV victimization in males [59], and six provided IPV perpetration estimates for males [57•, 59, 62, 69, 76, 78]. Two studies examined IPV perpetration in a non-stratified sample of males and females [56, 77].

In addition, the retrospective recall time period assessed varied by study. Nine studies examined lifetime history of IPV victimization or perpetration $[55,60-62,65,66,70$, $71 \cdot, 76], 10$ studies examined any reports in the past year $[56,57 \cdot, 59,61,64,67,72,75 \bullet, 76,77], 12$ studies reported on the past 6 months $[54,58,60,62-64,66,68,69,73,74$, 78 ], and three studies assessed some other recall period such as "at any time in your present relationship" [53, 55, 67].

Finally, while some studies operationalized IPV as any form of abuse that might have included physical, sexual, psychological abuse, or stalking $(n=14)[55,59-64,66,68,71 \bullet$, 


\section{PRISMA Flow Diagram}

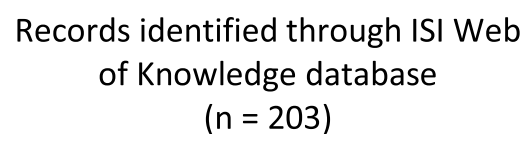

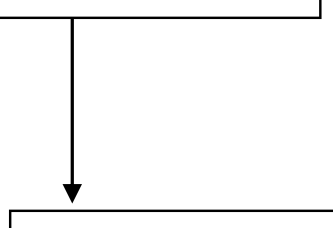

\section{Records identified through \\ PsycINFO database}

$(n=205)$

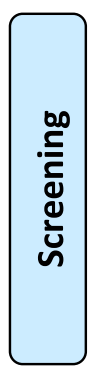

Records screened by abstract

$$
(n=128)
$$

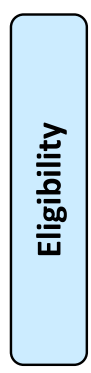

Full-text articles assessed

for eligibility; duplicates

removed

$(n=80)$

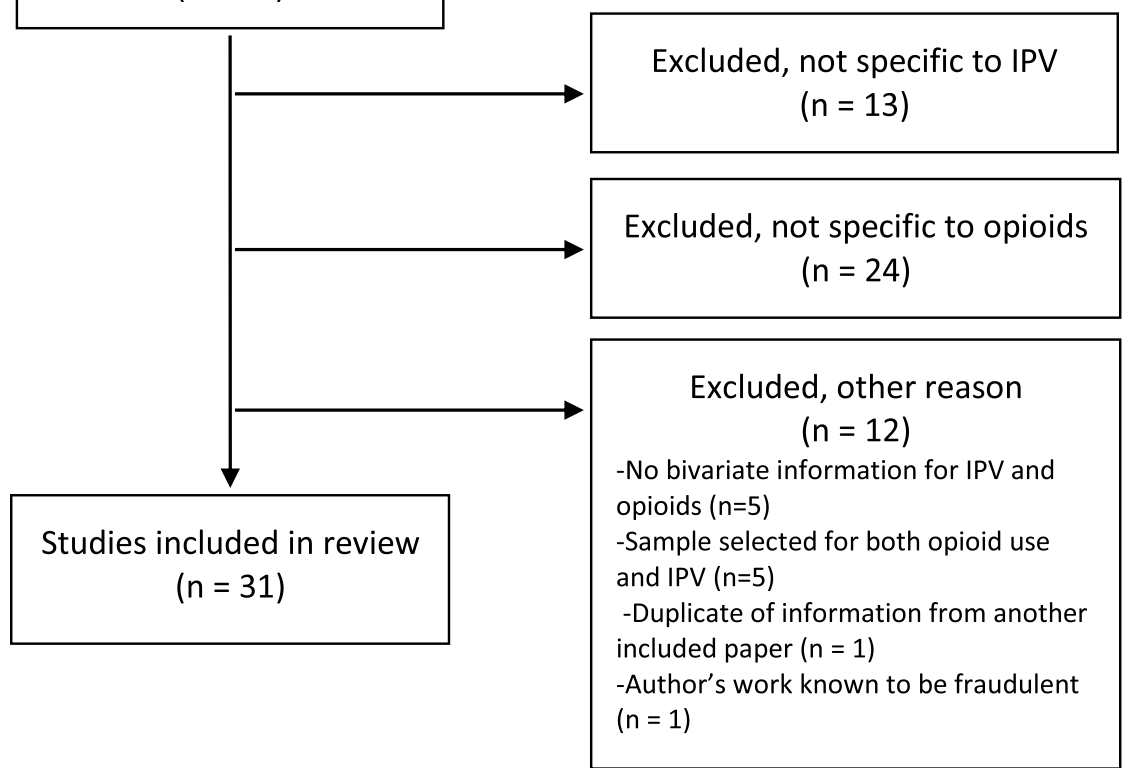

Fig. 1 Other reason includes the following: no bivariate information for IPV and opioids $(n=5)$, sample selected for both opioid use and IPV ( $n=5)$, duplicate of information from another included paper $(n=1)$, or author's work known to be fraudulent $(n=1)$

$73,74,75 \cdot, 77]$, other studies presented estimates for specific forms of IPV including physical abuse $(n=16)[54,56-60$, $62,65,67,69,70 \cdot 71 \bullet, 72,73,76,78]$, sexual abuse $(n=7)$ $[59,60,62,65,67,71 \cdot, 73]$, psychological abuse $(n=1)[71 \bullet]$, or stalking $(n=1)[71 \bullet]$. Many of the studies did not provide information about how opioid use was assessed nor provide the recall period that was used for opioid use assessment (e.g., lifetime vs. past year).

Considering all studies collectively, irrespective of the type of IPV assessed or length of the recall period, the prevalence of victimization ranged widely, from a low of $6 \%$ of women reporting sexual IPV victimization prior to the past year (but 
Table 1 Summary of literature on IPV and opioids, 1998 to 2018

Author, year Sample

Year(s) data

collected
Age of

participants

(years)

Question A. What is the prevalence of opioid use, given IPV?

A1 Caldentey et al. 52 Spanish women $18+$ years old who (2016)

2013-2015 disorder diagnosis, no severe cognitive disorders, and were hospital patients

A2 Smith, Homish,

25,778 men and women $18+$ years old

Leonard, and

Cornelius (2012)

[49]

who reported being in a relationship

during the past year and were

NESARC respondents

2004-2005

[perpetrators]

38.3

$(\mathrm{SD}=0.22)$

[victims]

Key findings 
Table 1 (continued)

Author, year

Sample

Year(s) data

collected
A5 Wuest et al. (2008) 292 adult community women separated 2004-2006 [52] from abusive partners on average

20 months and screened positive for IPV victimization; and chronic pain data was available
Question B: What is the prevalence of IPV, given opioid use?

B1 Balaji et al. (2016) 295 adult Tanzanian women who use drugs

B2 Brewer et al. (1998) [54]

B3 Campbell et al. (2012) [55]

B5 Crane et al. (2016) [57•]

B6 de Dios et al. (2014) [58]

B7 El-Bassel et al. (2005a) [63]

B8 El-Bassel et al. (2005b) [64]

82 mothers of children between the ages of 3-14 years old who were in MT, daily use of opiates at time of prior opiate use enrolled in drug treatment and had intercourse with a male partner in 6 months prior to study entry, no major cognitive impairment, not pregnant or trying to become pregnant

B4 Crane et al. (2014) 527 adults court-ordered to substance an OUD in Connecticut users, received an OUD diagnosis, and provided complete data or Massachusetts MT admission and at least 1 year of

513 adult women, English-speaking, 2004-2005 one or more occasion of unprotected [56] abuse interview and diagnosed with

999-2008

\footnotetext{
Mean age $=31.4$ $(\mathrm{SD}=10.3)$, range $=18-71$
}

$1999-2008$ men and 26 women who were
current methadone or buprenorphine

203 participants in a smoking cessation N/A study receiving MT in Rhode Island

405 women enrolled in New York City 1997-2000 MT; between the ages of 18 and 55, had intimate partnership in past year.

416 women in MT for at least 3 months $1997-2000$ $(\mathrm{SD}=9.5)$, range $=18-71$ $(\mathrm{SD}=9.6)$

Mean age $=39.9$ $(\mathrm{SD}=6.7)$, range $18-55$
Age of

participants

(years)
Mean age $=39.4$ $(\mathrm{SD}=9.9)$, range $=19-63$

Mean age $=\mathrm{N} / \mathrm{A}$ $91 \%$ between 20 and 40 years old

Mean age $=34.0$ $(\mathrm{SD}=4.9)$ $46 \%$ were $40+$ years old
Mean age $=\mathrm{N} / \mathrm{A}$,

Key findings

opium ( $4 \%$ vs $0.4 \%$ ) use than participants with no IPV.

$100 \%$ of sample experienced IPV in past 3 years or more recently.

$7 \%$ used prescription opioid analgesics in past month; opioid use was related to chronic pain grade.

$21 \%$ of those with highest level of chronic pain used prescription opioids in the past month, and $1 \%$ of those in lowest grade used opioids in the past month (grades 0 through 4)

Severity of IPV were associated with higher chronic pain; severity of injuries associated with higher chronic pain.

7\% of women in MT reported IPV victimization in past 3 months

$35 \%$ of women reported physical IPV victimization in the past 6 months $29 \%$ of women reported physical IPV perpetration in the past 6 months

$29 \%$ reported a history of IPV sexual or physical abuse victimization with their current main male partner

Those with an OUD had 1.66 increased odds of physical IPV perpetration in the past year as compared with drug offenders with other substance use disorders (OR 1.66, 95\% CI $0.87-3.15)$

Mean age $=31.1 \quad 20 \%$ of males and $58 \%$ of females (32\% of all respondents) reported perpetrating physical IPV in the past year

Mean age $=39.4 \quad 11 \%$ of participants had experienced

Mean age $=39.9$ $(\mathrm{SD}=6.7)$, range 18-55 physical IPV victimization (or threat of physical IPV) in the past 6 months; $12 \%$ of females; $9 \%$ of males

The prevalence of physical and/or sexual IPV victimization in past 6 months was $46 \%$,

$41 \%$ and $31 \%$ at baseline, $6-$ and 12-month follow-up, respectively.

$46 \%$ experienced physical and/or sexual IPV victimization in past 6 months; 
Table 1 (continued)

Author, year
Sample
Year(s) data collected
Age of

participants

(years)
B9 El-Bassel et al. (2004a) [60]

B10 El-Bassel et al. (2004b)

B11 El-Bassel et al. (2001) [59]
332 sexually active males age $18+$, in MT for 3 months, had an IP in past year.

999-2002

416 women in MT for at least 3 months with a past year IP

$1997-2000$

Mean age $=39.9$ $(\mathrm{SD}=6.7)$
Mean age $=43.3$
$(\mathrm{SD}=8.2)$

Women who reported physical or sexual IPV at wave 2 were more likely than women who did not report IPV to indicate frequent use of heroin at wave $3(\mathrm{OR}=2.7 ; 95 \%$ $\mathrm{CI}=1.1,6.5 ; p=0.04)$.

$28 \%$ of men reported any physical IPV perpetration in past 6 months, $7 \%$ severe physical IPV perpetration, and $10 \%$ injurious IPV perpetration, $24 \%$ paid for partner's drugs

Women reported prevalence of IPV victimization by subtype in past 6 months and lifetime

Past 6 months:

$31 \%$ sexual IPV victimization

$31 \%$ physical IPV victimization

$18 \%$ injurious IPV victimization

$47 \%$ any IPV victimization

Lifetime:

$46 \%$ sexual IPV victimization

$53 \%$ physical IPV victimization

$42 \%$ injurious IPV victimization

$88 \%$ any IPV victimization

Mean age $=41.3 \quad$ Men reported on prevalence of IPV

$(\mathrm{SD}=7.62)$

perpetration in past year.

$34 \%$ perpetrated any IPV,

$20 \%$ perpetrated minor physical IPV,

$15 \%$ perpetrated severe physical IPV or made a gun $/$ knife threat

$35 \%$ experienced female-perpetrated IPV victimization,

$15 \%$ experienced female-perpetrated minor abuse IPV victimization, and

$21 \%$ experienced severe IPV victimization.

(Severe IPV = Kicked, slammed against a wall, beat up, burned or scalded on purpose, choked, punched, hit with something that could hurt, or used or threatened to use a knife or gun on intimate partner; Minor IPV=Pushed, grabbed, twisted an arm or hair, thrown something that could hurt, or slapped intimate partner)

If men reported IPV perpetration, their risk of HIV risk-related behaviors such as having more than one partner, anal sex, exchanging sex for money or drugs in the past 6 months, was substantially elevated.

Mean age $=43.6$

$(\mathrm{SD}=8.5)$
Men reported on prevalence of IPV perpetration in past 6 months and lifetime.

Past 6 months:

$38 \%$ any IPV perpetration

$8 \%$ any severe IPV perpetration

$27 \%$ physical IPV perpetration 
Table 1 (continued)

Author, year

Sample

Year(s) data

collected

Age of

participants

Key findings

(years)

B13 El-Bassel, et al. (2000) [61]

B14 El-Bassel et al. (2001) [59]

B15 Engstrom et al. (2008) [66]
145 adult women in MT between the ages of $18-55$, sexually active with a male partner, not consistently using condom in the past 3 months and one of seven HIV risk behaviors.

280 women from three MT programs in 1995-1996 New York city, 18-55 years old, sexually active, not always using condoms consistently past 3 months, one more of seven HIV risk behaviors

1995-1996
Mean age $=40.7$ $(\mathrm{SD}=6.7)$, range $=18-55$
$7 \%$ any severe physical IPV $21 \%$ sexual IPV perpetration $2 \%$ severe sexual IPV perpetration $10 \%$ injurious

$3 \%$ severe injurious

Lifetime:

$58 \%$ any IPV perpetration $17 \%$ any severe IPV perpetration 49\% physical IPV perpetration $16 \%$ any severe physical IPV $32 \%$ sexual IPV perpetration $4 \%$ severe sexual IPV perpetration $19 \%$ injurious

$5 \%$ severe injurious

In addition, if both partners in a couple used heroin in the past 6 months, the adjusted odds of the man's severe IPV perpetration was $6.8(95 \% \mathrm{CI}$ 1.9, 24.6); if only the female partner used heroin, the risk of his severe IPV perpetration was AOR 6.7 (95\% CI $0.8,56.3)$, the male's use was not statistically significantly related to IPV perpetration; note that marijuana use was not associated with IPV perpetration

Mean age $=38.5, \quad 75 \%$ reported any IPV victimization in range $=18-55 \quad$ lifetime and $32 \%$ reported any IPV victimization in the past year.

4\% reported life-threatening IPV victimization more than five times in the past year.

$62 \%$ reported that their current intimate partner also had a drug or alcohol problem.

$32 \%$ of the sample reported having traded sex for money or drugs in the past year.

Of those who had traded sex,

$53 \%$ had ever experienced lifetime physical IPV victimization whereas

$37 \%$ of those who had not traded sex had lifetime physical IPV victimization experience.

Of those who had traded sex,

$44 \%$ had lifetime sexual IPV victimization experience whereas

$27 \%$ of those who had not traded sex had sexual IPV victimization

IPV victimization was associated with psychological distress. $(\mathrm{SD}=6.7)$, range $=18-55$ psychological, physical or sexual City, 18-55 years old, MT for 3 or more months, had an IP in past year
Mean age $=39.9 \quad 90 \%$ reported lifetime history of

1998 IPV victimization, with up to three main partners

$78 \%$ reported such IPV victimization in past 6 months

$82 \%$ also reported positive social support from their partners. 
Table 1 (continued)

Author, year

Sample
Year(s) data collected
Age of

participants

(years)

B16 Frye et al. (2001) 206 adult women in MT at one of three [67]
NYC programs, had a partner in the past year
1997

$\begin{array}{ll}\text { [67] } & \begin{array}{l}\text { NYC programs, had a partner in the } \\ \text { past year }\end{array}\end{array}$

B17 Gilbert et al. (2012) 241 low-income urban women [68] receiving emergency care from an emergency department in Bronx, New York.
Mean age $=32.8$ $(\mathrm{SD}=10.08)$, range $=18$ to 61
Key findings
IPV victimization in past year: $9 \%$ of women reported sexual IPV $38 \%$ reported sexual coercion, $38 \%$ reported sexual assault or coercion,

$50 \%$ reported physical IPV.

Prior to the past year but not within the past year,

$6 \%$ reported sexual IPV,

$10 \%$ sexual coercion,

$13 \%$ sexual assault or coercion,

$31 \%$ reported physical IPV victimization.

In the lifetime of the relationship,

$47 \%$ reported any sexual IPV

$65 \%$ reported physical IPV victimization.

Childhood sexual abuse and living in extreme poverty elevated risk that women would report IPV victimization.

Heroin use was a risk for subsequent IPV, but IPV victimization was not a risk for subsequent heroin use. Women who reported using heroin within the previous 6 months at Wave 1 were twice as likely as non-heroin-using women to report any IPV (RR: 2.1, 95\% CI 1.2, 3.6) and were 2.7 times more likely to report that they had sustained an injury from IPV (95\% CI 1.1, 6.5) at subsequent waves.

No support was found for associations between experiencing any IPV at Wave 1 and subsequent use of any illicit drug, marijuana, heroin, crack, cocaine, and/or hard drug.

**The finding that a woman's use of heroin increases the odds of her experiencing any IPV and injurious IPV is contrary to findings from a meta-analytic review (Moore et al., 2008) which suggests that women's heroin use is not associated with IPV.**

Prevalence of perpetrating physical and/or injurious IPV in past 6 months:

$28 \%$ at baseline

$34 \%$ at 6 -month follow-up

$31 \%$ at 12 -month follow-up

B19 Hall, Golder, 406 women on probation and parole

Mean age $=37.2$

$94 \%$ had lifetime physical IPV victimization experience Logan (2016) [70•]
$(\mathrm{SD}=10.2)$ vs. $87 \%$ of women with no NPOU had lifetime physical IPV victimization experience; Women who reported lifetime NPOU were more likely to 
Table 1 (continued)

Author, year

Sample

Year(s) data

collected

Age of

participants

Key findings

(years)

B20 Jackson and

Shannon (2015)

[71•]

B21 Lund et al. (2012)

[72]

]

(2012)

opioid-injecting men from the

Republic of Georgia

2006-2009

114 pregnant women voluntarily

enrolled in a MT program

2005-2007$$
\text { (n) }
$$

40 non-drug-using female partners of

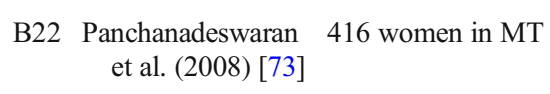
B23 Shannon et al. (2016) [75•]

B26 Whiteside et al. (2013) [77]

B24 Schiff et al. (2002) [74]

B25 Subodh et al. (2014) [76]

\author{
77 pregnant women who are 18+ years 2005-2007 \\ old, undergoing inpatient MT at an \\ Appalachian medical center, rural \\ residents
}
378 women in MT who had a male main partner

N/A

267 wives of men seeking addiction treatment in India

2011-2012

1999-2002
Mean age $=39.8$ $(\mathrm{SD}=6.7)$, range $=22-55$

Mean age $=32.3$ $(\mathrm{SD}=6.7)$

Mean age $=25.2$
$(\mathrm{SD}=3.99)$

have lifetime experience of physical IPV $\left(\chi^{2}=5.6, p<0.05\right)$.

$93 \%$ lifetime prevalence of IPV victimization (psychological, physical, sexual, stalking)

$51 \%$ psychological IPV victimization in lifetime

$69 \%$ physical IPV victimization in lifetime

$36 \%$ sexual IPV victimization in lifetime

$52 \%$ stalking by an intimate partner in lifetime

$54 \%$ lifetime prevalence of injury from IPV victimization

$42 \%$ of women reported physical IPV victimization by their partner within the last year

$48 \%$ of women said they felt unsafe in their current relationship

Prevalence of IPV victimization in past 6 months:

$45 \%$ any IPV

$39 \%$ physical IPV

$31 \%$ sexual IPV

$16 \%$ injurious IPV

Mean age $=24.9675 \%$ experienced past year IPV,

$(\mathrm{SD}=3.83) \quad$ including psychological abuse

$39 \%$ experienced past year physical, sexual or stalking victimization from IP

$23 \%$ sustained injuries from IPV

Mean age $=39.85 \quad 42 \%$ reported physical or sexual IPV in $(\mathrm{SD}=6.76), \quad$ past 6 months. range $=18-55$

Mean age $=35.13$ $(\mathrm{SD}=9.01)$ range $=19-63$

$14 \%$ of men in opioid treatment perpetrated physical IPV against wives in past year

$42 \%$ of men in treatment perpetrated physical IPV in lifetime against wives

2010-2011
Mean age $=17.5$ $(\mathrm{SD}=2.0)$, range $=14-20$

$34 \%$ of patients reporting past-year NPOU also reported past-year dating violence involvement (i.e., perpetration or victimization)

$14 \%$ of those with no past-year NPOU reported dating violence involvement $(p<0.001)$.

Abbreviations: $A O R$ adjusted odds ratio, $C I$ confidence interval, IP intimate partner, IPV intimate partner violence, $M T$ MT, N/A not available, $N E S A R C$ National Epidemiological Survey on Alcohol and Related Conditions, NPOU nonmedical prescription opioid use, NPSU non-prescription sedative use, $O R$ odds ratio, $O U D$ opioid use disorder, $R R$ relative risk, $S D$ standard deviation

not within the past year) [67] to a high of $94 \%$ for lifetime physical IPV among women who had ever used nonprescription opioids in their lifetimes [70•] (Table 2). Similarly, estimates of IPV perpetration ranged from $3 \%$ of men reporting severe, injurious IPV perpetration in the past 6 months [62] to 58\% of women reporting any form of IPV perpetration in the past year [57०] (Table 2). One study conducted in Tanzania [53] appears to be an outlier; it found a 7\% 
Table 2 Summary of study findings on IPV perpetration and victimization in samples of people who used opioids ${ }^{\dagger}(n=29$ studies)

\begin{tabular}{|c|c|c|c|c|c|}
\hline & $\begin{array}{l}\text { Victimization } \\
(n=20)\end{array}$ & $\begin{array}{l}\text { Range of victimization } \\
\text { prevalence estimates }\end{array}$ & $\begin{array}{l}\text { Perpetration } \\
(n=9)\end{array}$ & $\begin{array}{l}\text { Range of perpetration } \\
\text { prevalence estimates }\end{array}$ & $\begin{array}{l}\text { All } \\
(n=29)\end{array}$ \\
\hline \multicolumn{6}{|c|}{ Gender of study participants } \\
\hline Female & 18 & 7-93\% & 2 & $29 \%$ & 20 \\
\hline Male & 2 & $9-35 \%$ & 6 & $2-58 \%$ & 8 \\
\hline Females and males & 0 & $34 \%$ & 2 & $34 \% \%^{\dagger}$ & 2 \\
\hline \multicolumn{6}{|c|}{ Time period of reported IPV } \\
\hline Lifetime & 8 & $36-94 \%$ & 2 & $42-58 \%$ & 9 \\
\hline Past year & 7 & $23-75 \%$ & 3 & $14-58 \%$ & 10 \\
\hline 6 months & 9 & $9-78 \%$ & 3 & $3-38 \%$ & 12 \\
\hline Other time period & 3 & $7-29 \%$ & 0 & - & 3 \\
\hline \multicolumn{6}{|l|}{ Form of IPV } \\
\hline Multiple forms ${ }^{*}$ & 11 & $7-93 \%$ & 3 & $34-58 \%$ & 14 \\
\hline Physical only & 9 & 9-94\% & 8 & $3-49 \%$ & $16^{* *}$ \\
\hline Sexual only & 6 & $6-46 \%$ & 1 & $2-32 \%$ & 7 \\
\hline Psychological only & 1 & $51 \%$ & 0 & - & 1 \\
\hline Stalking only & 1 & $52 \%$ & 0 & - & 1 \\
\hline
\end{tabular}

${ }^{\dagger}$ Estimates derived from studies B1 to B29 (Table 1); excludes studies that presented odds ratios or relative risk estimates and no prevalence estimates

* This category describes IPV that was operationalized as any combination of two or more of the following forms: physical, sexual, psychological abuse or stalking, or studies that did not describe how IPV was operationalized

** Do not sum because some papers included both physical only victimization and physical only perpetration

prevalence rate of physical IPV victimization in the past 3 months among the subsample of women in their research study who were receiving methadone treatment. Setting aside the results of that one study, the prevalence of IPV victimization of any type among women was 36-94\% in their lifetimes, and $32-75 \%$ in the past year (Table 1). For men, the prevalence of IPV perpetration ranged from $15 \%$ perpetrating severe physical IPV or a gun/knife threat in the past year to $58 \%$ reporting any IPV perpetration in their lifetimes (Table 2).

Of particular note were the findings from a longitudinal study by Gilbert et al. [68] which reported that women who reported using heroin in the previous 6 months at Wave 1 were twice as likely as non-heroin-using women to report any IPV at Wave 2, 6 months later, and were 2.7 times more likely to report that they had sustained an IPV-related injury. Also of interest were the findings from the Crane et al. [56] study that found those with an OUD had a 1.6 increased odds of past year physical IPV perpetration as compared with criminal drug offenders with other substance use disorders (Table 2).

\section{Discussion}

Characterizing the literature on opioids and IPV is challenging for several reasons. First, the number of studies on opioid use among IPV survivors or perpetrators is very small. Second, while there have been 26 studies of IPV among people who have used opioids, the vast majority of those studies were surveys of people receiving methadone treatment and they may not be representative of all people with OUDs. Moreover, there are many dissimilarities in the way that the studies of IPV among people with OUDs have operationalized IPV and assessed when in subjects' lives IPV occurred. In other words, some studies define IPV as inclusive of psychological, physical, and sexual violence that has occurred at any time in a person's life, while others have defined it narrowly as physical violence in the preceding few months. Naturally, the estimates derived from such dissimilar methods diverge wildly and summarizing the existing literature using reported ranges of IPV results in very wide, virtually meaningless intervals. Nevertheless, synthesizing the results-that is, looking not only at the range but the preponderance of evidence-leaves little doubt that it is more likely than not that a woman in methadone treatment has experienced IPV victimization in her lifetime, and is very probable that she experienced it in the past year. What's more, a sizable percentage of men and women in methadone treatment have reported perpetration IPV during their lifetimes, and within the past year.

It is not surprising that studies of IPV have found that both victimization and perpetration experiences are common among people in methadone treatment. Prior research suggests that methadone treatment patients tend to be poor, suffering from comorbid mental and physical health problems, and living with numerous adverse conditions [79-83]. The gendered pathways theory of crime, for example, posits that 
experiences with childhood abuse, substance abuse, poverty, dysfunctional families, and abusive intimate relationships set women on pathways to criminal involvement [84-86]. Salisbury and Van Voorhis [87] have uncovered three path models linking childhood abuse, depression and anxiety, and substance abuse to women's imprisonment. Women's dysfunctional intimate relationships also promoted women's reoffending through increased risk of adult victimization, reduced self-efficacy, and addictive behavior. These findings, among others, indicate a tight entanglement of victimization, mental and physical health problems, and substance abuse, especially for women.

There is little question that those in methadone treatment are often in need of trauma-informed interventions to improve multiple conditions of their lives. El-Bassel and coinvestigators have been prolific on this topic and made a number of rigorous contributions to the literature that remain a solid foundation upon which to build in new directions. Investing additional research dollars in answering questions such as the following: "Are people who are receiving substance abuse treatment for OUD more likely than people in the general population to be struggling with the after effects of IPV victimization?" or "Are people who are receiving substance abuse treatment for OUD in need of trauma-informed care?" would be unlikely to uncover new information and therefore would waste precious resources. Similarly, investing in research to ascertain whether people in substance abuse treatment programs, or living with an SUD, have elevated odds of having perpetrated IPV at some point in their lives, or within the past year, is not likely to result in novel results that move the field forward substantially. Our review of the existing literature suggests that it would be reasonable to assume that those with OUDs could benefit from interventions designed to improve the health of intimate relationships. Our synthesis suggests it would be safe to move forward with the development and testing of strategies to accomplish better relationship health for those with OUDs, rather than investing in more etiological research about why people with OUDs appear to be at increased risk of unhealthy relationship behavior, or granular-level research about precisely what types of IPV they may have perpetrated or experienced and when.

On the other hand, additional research about the prevalence of IPV victimization and/or perpetration, and studies about why and how IPV experiences exacerbate risk for OUDs or continued opioid dependence, are urgently needed. Francis S. Collins, Director of NIH, has called not only for more pain research, but research into behavioral risk factors for substance abuse and dependence, saying "The urgency and scale of this crisis calls for innovative scientific solutions, from prevention to intervention and treatment. ... We must, however, prevent addictions before they start" [88]. To our knowledge, there have only been five studies published in peerreviewed journals in the past 20 years that provide estimates of opioid use history among people who have either perpetrated or experienced IPV - and these five studies did not use uniform definitions of IPV, opioid use, or similar recall periods - so the results are not easy to compare or to use collectively for inferences. Given the extent of the opioid epidemic, and the paucity of research on OUD among people who have either perpetrated or experienced IPV, the NIH, US Centers for Disease Control and Prevention, and private sector should prioritize research that would answer groundbreaking questions such as "Why do IPV survivors appear to be at increased risk for OUD, and how might we reduce their vulnerability?" or "What are the barriers that survivors and perpetrators of IPV face when they attempt to reduce or quit opioid use, and why do they continue use or relapse? In what ways, precisely, do unhealthy intimate partnerships exacerbate risk for OUD?" These remain unanswered questions for the field and empirical answers would be valuable.

The literature on IPV and SUD in general has found mixed results regarding the timing of victimization and development of SUD. There is evidence that drug use may precede abuse by an intimate partner [63, 89], as well as evidence that experiencing IPV is related to later drug use [63]. The relationship between IPV and SUD is best described as bidirectional [90-92]. The relationship may also be mediated by the abusive partners' substance use [93-95]. There is some evidence that abusive partners may exercise control by introducing their partners to drugs, forcing or coercing their partners to use, using drug history as a threat (e.g., threatening with arrest, deportation, or loss of child custody), and sabotaging treatment and recovery efforts [96]. Qualitative inquiries highlight the physical and social isolation of women in abusive relationships, which results in low social support, and a desire to demonstrate "respectability" by keeping their partnership intact [97-99]. Women also explained how substance use increased violence, paranoia, and jealousy in the relationship, as well as heightened conflict during periods of withdrawal, if women were unable to procure more drugs, in arguments over sharing of drugs, and when women sought treatment [100]. These findings suggest that the period immediately before and at initiation of treatment may represent heightened risk of violence.

This systematic review faces several limitations. First, the underlying studies were disparate in a number of ways-so not only was it infeasible to conduct a meta-analysis, it was challenging to synthesize the literature. Nevertheless, it was possible to characterize the two subtopics of interest: opioid use among people who have experienced IPV, and IPV among people who have used opioids. Second, ranges of the prevalence of IPV among people in methadone treatment are very wide, because they reflect experiences of men and women, with different forms of IPV, over different periods of time. While it is tempting to recommend that additional research be conducted that uses uniform definitions, efforts to impose uniform definitions on IPV and sexual violence research 
studies previously have not been particularly successful. Third, systematically reviewing research literature is a subjective process with certain inherent limitations, including biases that might influence the location and selection of studies, and heterogeneity across papers that can make it difficult to synthesize [101].

\section{Conclusions}

Given the warranted recent attention to risk factors for and solutions to OUD, additional research on the issue of how common OUD is among IPV survivors and perpetrators, and how IPV experiences may influence people to continue opioid use, create barriers for OUD treatment, or affect children of IPV survivors with OUDs, will be important to the field.

\section{Compliance with Ethical Standards}

Conflict of Interest The authors declare that they have no conflict of interest.

Human and Animal Rights and Informed Consent This article does not contain any studies with human or animal subjects performed by any of the authors.

\section{References}

Papers of particular interest, published recently, have been

highlighted as:

- Of importance

-• Of major importance

1. National Institutes of Health. NIH launches HEAL initiative, doubles funding to accelerate scientific solutions to stem national opioid epidemic [Internet]. 2018 [cited 2018 Oct 4]. Available from: https://www.nih.gov/news-events/news-releases/nihlaunches-heal-initiative-doubles-funding-accelerate-scientificsolutions-stem-national-opioid-epidemic. Accessed 1 Oct 2018.

2. Centers for Disease Control and Prevention. 2018 Annual surveillance report of drug-related risks and outcomes-United States. Surveillance Special Report. Centers for Disease Control and Prevention, U.S. Department of Health and Human Services; 2018. Available from: https://www.cdc.gov/drugoverdose/pdf/ pubs/2018-cdc-drug-surveillance-report.pdf. Accessed 1 Oct 2018.

3. Lewis B, Hoffman LA, Nixon SJ. Sex differences in drug use among polysubstance users. Drug Alcohol Depend. 2014;145: 127-33.

4. Jones CM. The paradox of decreasing nonmedical opioid analgesic use and increasing abuse or dependence - an assessment of demographic and substance use trends, United States, 20032014. Addict Behav. 2017;65:229-35.

5. Jones CM, Logan J, Gladden RM, Bohm MK. Vital signs: demographic and substance use trends among heroin users-United States, 2002-2013. MMWR Morb Mortal Wkly Rep. 2015;64: 719-25.
6. Marsh JC, Park K, Lin Y-A, Bersamira C. Gender differences in trends for heroin use and nonmedical prescription opioid use, 2007-2014. J Subst Abus Treat. 2018;87:79-85.

7. Cicero TJ, Ellis MS, Surratt HL, Kurtz SP. The changing face of heroin use in the United States: a retrospective analysis of the past 50 years. JAMA Psychiatry. 2014;71:821-6.

8. Florence CS, Zhou C, Luo F, Xu L. The economic burden of prescription opioid overdose, abuse, and dependence in the United States, 2013. Med Care. 2016;54:901-6.

9. Kolodny A, Courtwright DT, Hwang CS, Kreiner P, Eadie JL, Clark TW, et al. The prescription opioid and heroin crisis: a public health approach to an epidemic of addiction. Annu Rev Public Health. 2015;36:559-74.

10. Van Zee A. The promotion and marketing of OxyContin: commercial triumph, public health tragedy. Am J Public Health. 2009;99:221-7.

11. Powers RA, Kaukinen CE. Trends in intimate partner violence: 1980-2008. J Interpers Violence. 2012;27:3072-90.

12. Straus MA, Gelles RJ, Steinmetz SK. Behind closed doors: violence in the American family. Transaction ed. New Brunswick, N.J: Transaction Publishers; 2006.

13. Smith SG, Chen J, Basile KC, Gilbert LK, Merrick MT, Patel N, et al. The national intimate partner and sexual violence survey (NISVS): 2010-2012 state report. National Center for Injury Prevention and Control, Centers for Disease Control and Prevention: Atlanta; 2017.

14. Max W, Rice DP, Finkelstein E, Bardwell RA, Leadbetter S. The economic toll of intimate partner violence against women in the United States. Violence Vict. 2004;19:259-72.

15. Arias I, Corso P. Average cost per person victimized by an intimate partner of the opposite gender: a comparison of men and women. Violence Vict. 2005;20:379-91.

16. Moore TM, Stuart GL, Meehan JC, Rhatigan DL, Hellmuth JC, Keen SM. Drug abuse and aggression between intimate partners: a meta-analytic review. Clin Psychol Rev. 2008;28:247-74.

17. Golding JM. Intimate partner violence as a risk factor for mental disorders: a meta-analysis. J Fam Violence. 1999;14:99-132.

18. Afifi TO, MacMillan H, Cox BJ, Asmundson GJG, Stein MB, Sareen J. Mental health correlates of intimate partner violence in marital relationships in a nationally representative sample of males and females. J Interpers Violence. 2009;24:1398-417.

19. Herrera Duran L, Falgas I, Cook B, Noyola N, Toro M, Alegria M. Chronic non-malignant pain (CNMP) and substance use disorders. Eur Psychiatry. 2016;33:S206.

20. Matta MS, Porter JR, Chintakrindi S, Cosby AG. Addictive behaviors and chronic pain in a high-risk population: the simple and confounding effects of multiple addictive diseases. J Drug Issues. 2016;46:135-47.

21. Campbell J, Jones AS, Dienemann J, Kub J, Schollenberger J, O'Campo P, et al. Intimate partner violence and physical health consequences. Arch Intern Med. 2002;162:1157.

22. Coker AL, Smith PH, Bethea L, King MR, McKeown RE. Physical health consequences of physical and psychological intimate partner violence. Arch Fam Med. 2000;9:451-7.

23. Coker AL, Davis KE, Arias I, Desai S, Sanderson M, Brandt HM, et al. Physical and mental health effects of intimate partner violence for men and women. Am J Prev Med. 2002;23:260-8.

24. Leserman J, Drossman DA. Relationship of abuse history to functional gastrointestinal disorders and symptoms: some possible mediating mechanisms. Trauma Violence Abuse. 2007;8:331-43.

25. Leserman J, Zolnoun D, Meltzer-Brody S, Lamvu G, Steege JF. Identification of diagnostic subtypes of chronic pelvic pain and how subtypes differ in health status and trauma history. Am J Obstet Gynecol. 2006;195:554-60 discussion 560-561.

26. Coker AL, Weston R, Creson DL, Justice B, Blakeney P. PTSD symptoms among men and women survivors of intimate partner 
violence: the role of risk and protective factors. Violence Vict. 2005;20:625-43.

27. Perez S, Johnson DM. PTSD compromises battered women's future safety. J Interpers Violence. 2008;23:635-51.

28. Woods SJ. Intimate partner violence and post-traumatic stress disorder symptoms in women: what we know and need to know. $\mathrm{J}$ Interpers Violence. 2005;20:394-402.

29. Devries KM, Mak JY, Bacchus LJ, Child JC, Falder G, Petzold M, et al. Intimate partner violence and incident depressive symptoms and suicide attempts: a systematic review of longitudinal studies. Tsai AC, editor. PLoS Med. 2013;10:e1001439.

30. Dillon G, Hussain R, Loxton D, Rahman S. Mental and physical health and intimate partner violence against women: a review of the literature. Int J Fam Med. 2013;2013:1-15.

31. Pico-Alfonso MA, Garcia-Linares MI, Celda-Navarro N, BlascoRos C, Echeburúa E, Martinez M. The impact of physical, psychological, and sexual intimate male partner violence on women's mental health: depressive symptoms, posttraumatic stress disorder, state anxiety, and suicide. J Women's Health. 2006;15:599-611.

32. Dutton MA, Green BL, Kaltman SI, Roesch DM, Zeffiro TA, Krause ED. Intimate partner violence, PTSD, and adverse health outcomes. J Interpers Violence. 2006;21:955-68.

33. Lai HMX, Cleary M, Sitharthan T, Hunt GE. Prevalence of comorbid substance use, anxiety and mood disorders in epidemiological surveys, 1990-2014: a systematic review and meta-analysis. Drug Alcohol Depend. 2015;154:1-13.

34. Swendsen J, Conway KP, Degenhardt L, Glantz M, Jin R, Merikangas KR, et al. Mental disorders as risk factors for substance use, abuse and dependence: results from the 10-year follow-up of the National Comorbidity Survey: mental disorders as risk factors for substance use. Addiction. 2010;105:1117-28.

35. Leonard KE, Eiden RD. Marital and family processes in the context of alcohol use and alcohol disorders. Annu Rev Clin Psychol. 2007;3:285-310.

36. Leonard KE, Quigley BM. Thirty years of research show alcohol to be a cause of intimate partner violence: future research needs to identify who to treat and how to treat them: alcohol and intimate partner violence. Drug Alcohol Rev. 2017;36:7-9.

37. Rothman EF, McNaughton Reyes L, Johnson RM, LaValley M. Does the alcohol make them do it? Dating violence perpetration and drinking among youth. Epidemiol Rev. 2012;34:103-19.

38. Stuart GL, O'Farrell TJ, Temple JR. Review of the association between treatment for substance misuse and reductions in intimate partner violence. Subst Use Misuse. 2009;44:1298-317.

39. Pihl R, Hoaken P. Biological bases to addiction and aggression in close relationships. In: Werkele C, Wall A, editors. Violence addict Equ Theor Clin issues Subst abuse Relatsh violence. Philadelphia: Brunner/Mazel; 2002. p. 25-43.

40. Stuart GL, Temple JR, Follansbee KW, Bucossi MM, Hellmuth JC, Moore TM. The role of drug use in a conceptual model of intimate partner violence in men and women arrested for domestic violence. Psychol Addict Behav. 2008;22:12-24.

41. Brady KT, Myrick H, McElroy S. The relationship between substance use disorders, impulse control disorders, and pathological aggression. Am J Addict. 1998;7:221-30.

42. Evren C, Yilmaz A, Can Y, Bozkurt M, Evren B, Umut G. Severity of impulsivity and aggression at a 12-month follow-up among male heroin dependent patients. Klin Psikofarmakol BülBull Clin Psychopharmacol. 2014;24:158-67.

43. Roozen HG, van der Kroft P, van Marle HJ, Franken IHA. The impact of craving and impulsivity on aggression in detoxified cocaine-dependent patients. J Subst Abus Treat. 2011;40:414-8.

44. Fischer JL, Fitzpatrick J, Cleveland B, Lee J-M, McKnight A, Miller B. Binge drinking in the context of romantic relationships. Addict Behav. 2005;30:1496-516.
45. Quigley BM, Leonard KE. Alcohol and the continuation of early marital aggression. Alcohol Clin Exp Res. 2000;24:1003-10.

46. White HR, Chen P-H. Problem drinking and intimate partner violence. J Stud Alcohol. 2002;63:205-14.

47. National Institute on Drug Abuse. Opioids [Internet]. n.d. [cited 2018 Oct 8]. Available from: https://www.drugabuse.gov/drugsabuse/opioids. Accessed 1 Oct 2018.

48. Caldentey C, Tirado-Muñoz J, Ferrer T, Fonseca F, Rossi P, Mestre-Pintó JI, et al. Intimate partner violence among female drug users admitted to the general hospital: screening and prevalence. Adicciones. 2017;29:172-9.

49. Smith PH, Homish GG, Leonard KE, Cornelius JR. Intimate partner violence and specific substance use disorders: findings from the National Epidemiologic Survey on alcohol and related conditions. Psychol Addict Behav. 2012;26:236-45.

50. Stene LE, Dyb G, Tverdal A, Jacobsen GW, Schei B. Intimate partner violence and prescription of potentially addictive drugs: prospective cohort study of women in the Oslo Health Study. BMJ Open. 2012;2:e00614.

51. Tran A, Lin L, Nehl EJ, Talley CL, Dunkle KL, Wong FY. Prevalence of substance use and intimate partner violence in a sample of A/PI MSM. J Interpers Violence. 2014;29:2054-67.

52. Wuest J, Merritt-Gray M, Ford-Gilboe M, Lent B, Varcoe C, Campbell JC. Chronic pain in women survivors of intimate partner violence. J Pain. 2008;9:1049-57.

53. Balaji D, Mlunde LB, Tran OC, Lambdin B, Mbwambo J, Nyandindi $C$, et al. First report of gender based violence as a deterrent to methadone access among females who use heroin in Dar es Salaam. Tanzania AIDS Behav. 2017;21:2093-100.

54. Brewer DD, Fleming CB, Haggerty KP, Catalano RF. Drug use predictors of partner violence in opiate dependent women. Violence Vict. 1998;13:107-15.

55. Campbell ANC, Tross S, Hu M, Pavlicova M, Nunes EV. Predictors of relationship power among drug-involved women. AIDS Behav. 2012;16:1532-41.

56. Crane CA, Oberleitner LMS, Devine S, Easton CJ. Substance use disorders and intimate partner violence perpetration among male and female offenders. Psychol Violence. 2014;4:322-33.

57. Crane CA, Schlauch RC, Devine S, Easton CJ. Comorbid substance use diagnoses and partner violence among offenders receiving pharmacotherapy for opioid dependence. J Addict Dis. 2016;35:205-11

A study examining opioid use and intimate partner violence in a sample of 81 offenders participating in court-ordered substance use interviews. Results indicate that one third of the sample evidenced recent involvement in partner violence, and likelihood of violence was increased by cocaine and benzodiazepine use.

58. de Dios MA, Anderson BJ, Caviness CM, Stein M. Intimate partner violence among individuals in methadone maintenance treatment. Subst Abus. 2014;35:190-3.

59. El-Bassel N, Fontdevila J, Gilbert L, Voisin D, Richman BL, Pitchell P. HIV risks of men in methadone maintenance treatment programs who abuse their intimate partners: a forgotten issue. J Subst Abus. 2001;13:29-43.

60. El-Bassel N, Gilbert L, Frye V, Wu E, Go H, Hill J, et al. Physical and sexual intimate partner violence among women in methadone maintenance treatment. Psychol Addict Behav. 2004;18:180-3.

61. El-Bassel N, Gilbert L, Schilling R, Wada T. Drug abuse and partner violence among women in methadone treatment. J Fam Violence. 2000;15:209-28.

62. El-Bassel N, Gilbert L, Wu E, Chang M, Fontdevila J. Perpetration of intimate partner violence among men in methadone treatment programs in New York City. Am J Public Health. 2007;97:1230-2.

63. El-Bassel N, Gilbert L, Wu E, Go H, Hill J. Relationship between drug abuse and intimate partner violence: a longitudinal study 
among women receiving methadone. Am J Public Health. 2005;95:465-70.

64. El-Bassel N, Gilbert L, Wu E, Go H, Hill J. HIV and intimate partner violence among methadone-maintained women in New York City. Soc Sci Med. 2005;61:171-83.

65. El-Bassel N, Simoni JM, Cooper DK, Gilbert L, Schilling RF. Sex trading and psychological distress among women on methadone. Psychol Addict Behav. 2001;15:177-84.

66. Engstrom M, El-Bassel N, Go H, Gilbert L. Childhood sexual abuse and intimate partner violence among women in methadone treatment: a direct or mediated relationship? J Fam Violence. 2008;23:605-17.

67. Frye V, El-Bassel N, Gilbert L, Rajah V, Christie N. Intimate partner sexual abuse among women on methadone. Violence Vict. 2001;16:553-64.

68. Gilbert L, El-Bassel N, Chang M, Wu E, Roy L. Substance use and partner violence among urban women seeking emergency care. Psychol Addict Behav. 2012;26:226-35.

69. Gilbert L, El-Bassel N, Wu E, Chang M. Intimate partner violence and HIV risks: a longitudinal study of men on methadone. J Urban Health. 2007;84:667-80.

70. Hall MT, Golder S, Higgins GE, Logan TK. Nonmedical prescription opioid use among victimized women on probation and parole. Addict Behav. 2016;53:113-9

A study of 406 victimized women on probation and parole. Results indicate that $41.6 \%$ of women reported lifetime non-prescription opioid use, and these women were more likely to be White, have poorer general health, and more severe psychological distress.

71. Jackson A, Shannon L. Factors associated with the chronicity of intimate partner violence experiences among pregnant women in detoxification services. Women Health. 2015;55:883-99

A recent study examining 114 pregnant women entering inpatient treatment in Kentucky. The research examines the relationship between partner violence, substance use, and pregnancy, and identifies prevention, intervention, and treatment implications.

72. Lund IO, Kirtadze I, Otiashvili D, O'Grady KE, Jones HE. Female partners of opioid-injecting men in the republic of Georgia: an initial characterization. Subst Abuse Treat Prev Policy. 2012;7:46.

73. Panchanadeswaran S, El-Bassel N, Gilbert L, Wu E, Chang M. An examination of the perceived social support levels of women in methadone maintenance treatment programs who experience various forms of intimate partner violence. Womens Health Issues. 2008; 18:35-43.

74. Schiff M, El-Bassel N, Engstrom M, Gilbert L. Psychological distress and intimate physical and sexual abuse among women in methadone maintenance treatment programs. Soc Serv Rev. 2002;76:302-20.

75. Shannon L, Nash S, Jackson A. Examining intimate partner violence and health factors among rural Appalachian pregnant women. J Interpers Violence. 2016;31:2622-40

This study of 77 rural, Appalachian pregnant women is important for improving prevention and intervention around Neonatal Abstinence Syndrome (NAS). Results indicate that $75.3 \%$ of women experienced IPV in the past year and that this population is particularly high-risk and high-needs.

76. Subodh NB, Grover S, Grewal M, Grewal S, Basu D, Mattoo SK. Interpersonal violence against wives by substance dependent men. Drug Alcohol Depend. 2014;138:124-9.

77. Whiteside LK, Walton MA, Bohnert ASB, Blow FC, Bonar EE, Ehrlich P, et al. Nonmedical prescription opioid and sedative use among adolescents in the emergency department. Pediatrics. 2013;132:825-32.

78. El-Bassel N, Gilbert L, Golder S, Wu E, Chang M, Fontdevila J, et al. Deconstructing the relationship between intimate partner violence and sexual HIV risk among drug-involved men and their female partners. AIDS Behav. 2004;8:429-39.
79. Brooner RK, King VL, Kidorf M, Schmidt CW, Bigelow GE. Psychiatric and substance use comorbidity among treatmentseeking opioid abusers. Arch Gen Psychiatry. 1997;54:71-80.

80. De Maeyer J, Vanderplasschen W, Broekaert E. Quality of life among opiate-dependent individuals: a review of the literature. Int J Drug Policy. 2010;21:364-80.

81. Firoz S, Carlson G. Characteristics and treatment outcome of older methadone-maintenance patients. Am J Geriatr Psychiatry. 2004;12:539-41.

82. Puigdollers E, Domingo-Salvany A, Brugal MT, Torrens M, Alvarós J, Castillo $\mathrm{C}$, et al. Characteristics of heroin addicts entering methadone maintenance treatment: quality of life and gender. Subst Use Misuse. 2004;39:1353-68.

83. Ryan CF, White JM. Health status at entry to methadone maintenance treatment using the SF-36 health survey questionnaire. Addiction. 1996;91:39-46.

84. Chesney-Lind M. The female offender: girls, women, and crime. Thousand Oaks: Sage Publications; 1997.

85. Daly K. Women's pathways to felony court: feminist theories of lawbreaking and problems of representation. South Calif Rev Law Womens Stud. 1992;2:11-52.

86. Daly K. Gender, crime, and punishment. New Haven: Yale University Press; 1994.

87. Salisbury EJ, Van Voorhis P. Gendered pathways: a quantitative investigation of women probationers' paths to incarceration. Crim Justice Behav. 2009;36:541-66.

88. Collins FS. Statement from the NIH director on combating the opioid crisis with scientific solutions [Internet]. 2017 [cited 2018 Oct 8]. Available from: https://www.nih.gov/about-nih/who-weare/nih-director/statements/statement-nih-director-combatingopioid-crisis-scientific-solutions. Accessed 1 Oct 2018.

89. Testa M, Livingston JA, Leonard KE. Women's substance use and experiences of intimate partner violence: a longitudinal investigation among a community sample. Addict Behav. 2003;28:164964.

90. Bennett L, O'Brien P. Effects of coordinated services for drugabusing women who are victims of intimate partner violence. Violence Women. 2007;13:395-411.

91. Cohen LR, Field C, Campbell ANC, Hien DA. Intimate partner violence outcomes in women with PTSD and substance use: a secondary analysis of NIDA clinical trials network "women and trauma" multi-site study. Addict Behav. 2013;38:2325-32.

92. Kilpatrick DG, Acierno R, Resnick HS, Saunders BE, Best CL. A 2-year longitudinal analysis of the relationships between violent assault and substance use in women. J Consult Clin Psychol. 1997;65:834-47.

93. Golinelli D, Longshore D, Wenzel SL. Substance use and intimate partner violence: clarifying the relevance of women's use and partners' use. J Behav Health Serv Res. 2009;36:199-211.

94. González-Guarda RM, Peragallo N, Urrutia MT, Vasquez EP, Mitrani VB. HIV risks, substance abuse, and intimate partner violence among hispanic women and their intimate partners. J Assoc Nurses AIDS Care. 2008;19:252-66.

95. Lipsky S, Caetano R, Field CA, Larkin GL. Psychosocial and substance-use risk factors for intimate partner violence. Drug Alcohol Depend. 2005;78:39-47.

96. Warshaw C, Lyon E, Bland P, Phillips H, Hooper M. Mental health and substance use coercion surveys: report from the National Center on Domestic Violence, Trauma \& Mental Health and the National Domestic Violence Hotline [internet]: National Center on Domestic Violence, Trauma \& Mental Health; 2014 . Available from: http://www. nationalcenterdvtraumamh.org/wp-content/uploads/2014/10/ NCDVTMH NDVH MHSUCoercionSurveyReport 2014-2. pdf. Accessed 1 Oct 2018. 
97. El-Bassel N, Gilbert L, Rajah V, Foleno A, Frye V. Social support among women in methadone treatment who experience partner violence: isolation and male controlling behavior. Violence Women. 2001;7:246-74.

98. Illangasekare SL, Burke JG, Chander G, Gielen AC. Depression and social support among women living with the substance abuse, violence, and HIV/aids syndemic: a qualitative exploration. Womens Health Issues. 2014;24:551-7.

99. Rajah V. Respecting boundaries. Br J Criminol. 2006;46:837-58.

100. Gilbert L, El-Bassel N, Rajah V, Foleno A, Frye V. Linking drugrelated activities with experiences of partner violence: a focus group study of women in methadone treatment. Violence Vict. 2001;16:517-36.

101. Ganeshkumar P, Gopalakrishnan S. Systematic reviews and metaanalysis: understanding the best evidence in primary healthcare. $\mathrm{J}$ Fam Med Prim Care. 2013;2:9.

Publisher's Note Springer Nature remains neutral with regard to jurisdictional claims in published maps and institutional affiliations. 